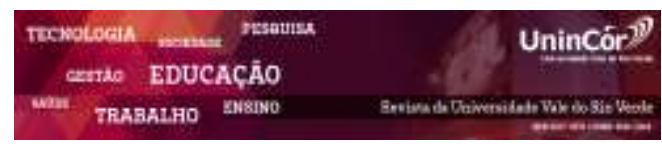

Revista da Universidade Vale do Rio Verde ISSN: 1517-0276 / EISSN: 2236-5362 Vol. 16 | n. 1 | Ano 2018

Rafael Pereira

Universidade Federal do Ceará rafaelpereirabiologo@gmail.com

Francisco Ângelo de Matos Neto Universidade Estadual Vale do Acaraú matosneto.bio@hotmail.com

Francisca Lidiane Linhares de Aguiar Universidade Federal do Ceará lidianelinhares@yahoo.com.br

Elnatan Bezerra de Souza Universidade Estadual Vale do Acaraú elbezsouza@yahoo.com.br

Hélcio Silva Santos Universidade Estadual Vale do Acaraú helciodossantos@gmail.com

Carolina Sidrim de Paula Cavalcante Universidade Federal do Ceará carolinaspc@yahoo.com.br

Raquel Oliveira dos Santos Fontenelle Universidade Estadual Vale do Acaraú raquelbios@yahoo.com.br

\section{ATIVIDADE ANTIFÚNGICA, SINERGISMO E CITOTOXICIDADE DO EXTRATO ETANÓLICO DA CASCA DE Myroxylon peruiferum L.f}

\begin{abstract}
RESUMO
Os vegetais são conhecidos por produzir grande variedade de compostos ativos que, atualmente têm se tornando importantes para a busca de novos fármacos. Diante do exposto, o objetivo deste trabalho foi avaliar a atividade biológica do extrato etanólico da casca de Myroxylon peruiferum L. f. A concentração inibitória mínima (CIM) e concentração fungicida mínima (MFC) foram determinadas pelo método de microdiluição em caldo. Enquanto que a análise para verificar o potencial sinérgico do extrato foi através do método chekerboard, e a atividade hemolítica foi determinada para analisar o perfil citotóxico da espécie estudada. $\mathrm{O}$ extrato bruto e a fração clorofórmio apresentaram $\mathrm{CIM} \leq 0,625$ $\mathrm{mg} \cdot \mathrm{mL}^{-1}$ e $\mathrm{MFC} \leq 1,25 \mathrm{mg} \cdot \mathrm{mL}^{-1}$. A fração acetato de etila apresentou $\mathrm{CIM} \leq 1,25 \mathrm{mg} \cdot \mathrm{mL}^{-1}$ e $\mathrm{MFC} \leq 2,5 \mathrm{mg} \cdot \mathrm{mL}^{-1}$. A atividade hemolítica mostrou que nas concentrações de 0,$039 ; 0,078 ; 0,156$; 0,$312 ; 0,625 ; 1,25$ e $2,5 \mathrm{mg} / \mathrm{mL}$, a percentual de hemólise variou entre $0,19 \%$ até $40,88 \%$, apresentando que o extrato é moderadamente citotóxico para os eritrócitos humanos. Neste contexto, a planta mostra-se como uma fonte promissora de matéria-prima na produção de novos medicamentos fitoterápicos, pois a espécie estudada mostra-se com relevantes atividades biológicas.
\end{abstract}

Palavras-chave: Infecções fúngicas. Microdiluição em cado. Citotoxicidade. Sinergismo. Medicina Popular.

\section{ANTIFUNGAL ACTIVITY, SYNERGISM AND CYTOTOXICITY OF THE ETHANOLIC EXTRACT OF THE Myroxylon peruiferum L.f}


Keywords: Fungal infections. Microdilution broth. Cytotoxicity. Synergism. Popular Medicine.

Recebido em: 26/11/2016 - Aprovado em: 11/01/2018 - Disponibilizado em: 15/07/2018

\section{INTRODUÇÃO}

Os vegetais são conhecidos por produzir grande variedade de compostos ativos que, atualmente têm se tornando importantes para a busca de novos fármacos. As moléculas são sintetizadas pelos vegetais no seu metabolismo secundário e são importantes por apresentar diversas propriedades biológicas (SILVA, 2010).

Pondere-se que pelo menos $25 \%$ de todos os medicamentos atuais é proveniente, direta ou indiretamente, de plantas medicinais (BRASIL, 2012). De acordo com a Organização Mundial de Saúde, essa percentagem pode ser superior a $60 \%$ no caso de classes de produtos farmacêuticos, como medicamentos antitumorais e antimicrobianos (WHO, 2011).

De acordo com a Organização Mundial de Saúde (OMS), as infecções causadas por microorganismos resistentes são consideradas um grande problema de saúde pública e frequentemente os pacientes não respondem bem ao tratamento convencional, resultando no prolongamento da doença e, consequentemente, aumentando o risco de morte do paciente. Além disso, os custos associados ao tratamento aumentam substancialmente quando microorganismos multirresistentes são os causadores da infecção (WORLD HEALTH ORGANIZATION, 2013).

Myroxylon peruiferum L.f. pertence à família Fabaceae (antiga Leguminosae e
Papilionoideae), conhecida popularmente como cabriúva, pau-de-bálsamo e bálsamo. É uma planta decídua, heliófita, possuindo cerca de 10 a 20 metros de altura. (LORENZI,MATOS, 2008).

Diante do exposto, o objetivo deste trabalho foi avaliar a atividade antifúngica, sinergismo e citotoxicidade do extrato etanólico da casca de M. peruiferum L. f.

\section{MÉTODOS}

Material vegetal e preparação do extrato

Casca de M. peruiferum L.f. foi coletada no maciço de Uruburetama, localizado no distrito de Soledade no município de Itapajé, sob as coordenadas $03^{\circ} 37^{\prime} 86^{\prime}$ 'S e $39^{\circ} 35^{\prime} 33^{\prime \prime}$ 'W, com altitude de $800 \mathrm{~m}$. A exsicata da planta encontrase arquivada no Herbário Prof. Francisco José de Abreu Matos da Universidade Estadual Vale do Acaraú, autenticada pelo Dr. E. B. Souza sob o tombo 19240. As cascas foram secas à temperatura ambiente e trituradas utilizando um moinho. Posteriormente, o material foi armazenado em recipiente com etanol por 4 dias. $\mathrm{O}$ extrato foi evaporado a vácuo utilizando um rotaevaporador.

Separação das frações

O extrato etanólico bruto $(100 \mathrm{~g})$, depois de concentrado a vácuo, foi cromatografado em coluna de sílica em gel com eluentes de 
polaridades crescente (clorofórmio, acetato de ética e metanol). As soluções foram novamente rotaevaporada para obter as frações do extrato bruto.

Ensaio in vitro da atividade antifúngica

Cepas fúngicas

Foram utilizadas cepas fúngicas de Candida albicans e dermatofíticas de Trichophyton rubrum. As cepas de C. albicans CLS 17:11 foram isoladas de pacientes da Santa Casa de Misericórdia de Sobral, Ceará, e mantidas em meio nutritivo a $20{ }^{\circ} \mathrm{C}$ no Laboratório de Microbiologia da Universidade Estadual Vale do Acaraú. As cepas de T. rubrum CEMM 05.1.034 são provenientes do Centro de Micologia de Recife, Pernambuco.

Preparação do inóculo para os testes de sensibilidade antifúngica

O inóculo foi preparado a partir de estirpes cultivadas em ágar Sabouraud para dermatófitos durante 5 dias a $35^{\circ} \mathrm{C}$ e estirpes de levedura durante $48 \mathrm{~h}$ a $24{ }^{\circ} \mathrm{C}$. Fragmentos de $T$. rubrum e C. albicans foram transferidos para tubos contendo $9 \mathrm{~mL}$ de solução salina para obter concentrações equivalente a $5 \times 10^{4} \mathrm{~mL}^{-1}$ ou de 0,5 escala de McFarland. A suspensão foi obtida por diluição 1:100 seguida de 1:20 da suspensão padrão para $C$. albicans e 1:5 para T. rubrum, ambos com meio RPMI 1640 com L-glutamina, sem bicarbonato de sódio, tamponado a pH 7,0 com MPOS (ácido 2-[N-morfolino]propanosulfônico; MPOS 0,165M), para obter concentrações do inóculo de aproximadamente $5,0 \times 10^{3}$ a $2,5 \times 10^{3}$ UFC. $\mathrm{mL}^{-1}$ para C. albicans e $5 \times 10^{4}$ UFC. $\mathrm{mL}^{-1}$ para $T$. rubrum (FONTENELLE et al., 2008).

\section{Método de microdiluição em caldo}

A concentração inibitória mínima (CIM) foi determinada pelo método descrito por Clinical and Laboratory Standards Institute-CLSI (CLSI M27-A2, 2008), enquanto que a concentração fungicida mínima (CFM) foi de acordo com Fontenelle et al. (2007). O extrato bruto e as frações clorofórmico, acetato de etila e metanólica foram preparadas em DMSO (Dimetilsufóxido). Foi inoculado $100 \mu \mathrm{L}$ de meio RPMI 1640 estéril em cada poço da placa de microdiluição, seguidos de $100 \mu \mathrm{L}$ da amostra adicionado à primeira coluna de micropoços e feitas diluições seriadas até a coluna 11, num intervalo de concentração de 10-0,009 mg. $\mathrm{mL}^{-1}$. Posteriormente, foram adicionados $100 \mu \mathrm{l}$ do inóculo em todos os poços perfazendo um volume final de $200 \mu \mathrm{L}$ por poço.

O antifúngico cetoconazol e a anfotericina B foram utilizados como controle positivo, num intervalo de 0,007-16 mg.mL $\mathrm{mL}^{-1}$ para o T. rubrum e C. albicans, respectivamente, e um controle negativo, o inóculo mais o RPMI. As placas foram incubadas a $37{ }^{\circ} \mathrm{C}$ durante 2 dias para as leveduras e de 5 dias para dermatófitos. Após o período, foi realizada a leitura visual das placas, observando-se a redução macroscopicamente do crescimento fúngico. A CIM foi definida pela menor fração-teste capaz de inibir o crescimento fúngico visualmente detectado. A concentração fungicida mínima (CFM) correspondeu como a menor concentração que resultou em um não crescimento fúngico após 2 dias para $C$. albicans e 5 dias para $T$. rubrum após a transferência de 
$100 \mu \mathrm{L}$ de solução a partir de poços sem turvação em ágar dextrose $28{ }^{\circ} \mathrm{C}$ (FONTENELLE et al., 2007, FONTENELLE et al., 2008).

\section{Sinergismo}

$\mathrm{O}$ efeito do composto combinado com antifúngico padrão foi determinado pela técnica do checkerboard, sendo este método utilizado para determinar a interação das drogas por meio do cálculo do Índice de Concentração Inibitória Fracional (FICI). O FICI é calculado pela adição da Concentração Inibitória Fracional (FIC) para cada composto testado, sendo definida como a adição dos valores de CIM de cada fármaco na combinação e CIM do mesmo produto sozinho (WHITE et al., 1996). Deste modo, o FIC será calculado:

$$
\begin{gathered}
\mathrm{FIC}^{\mathrm{A}}=\mathrm{MIC}^{\mathrm{A}} \text { combinado } / \mathrm{MIC}^{\mathrm{A}} \text { sozinho } \\
\mathrm{FIC}^{\mathrm{B}}=\mathrm{MIC}^{\mathrm{B}} \text { combinado } / \mathrm{MIC}^{\mathrm{B}} \text { sozinho } \\
\text { FICI }=\mathrm{FIC}^{\mathrm{A}}+\mathrm{FIC}^{\mathrm{B}}
\end{gathered}
$$

Para tanto, o A representa o extrato de $M$. peruiferum L.f. de acordo com a sua polaridade e o B o antifúngico padrão, o cetoconazol. A turbidez das suspensões fúngicas foram preparadas e ajustadas para 0,5 na escala McFarland $\left(10^{5} \mathrm{UFC} / \mathrm{mL}\right)$. Nas soluções foram utilizados os produtos testados, nas concentrações dos seus respectivos valores de CIM. Inicialmente $50 \mu \mathrm{L}$ do meio RPMI 1640 foram adicionados em todos os 96 poços da placa de microdiluição. Adicionaram-se então, na primeira coluna $50 \mu \mathrm{L}$ do extrato no qual foram realizadas diluições em série na placa até a $8^{\mathrm{a}}$ coluna. Em linhas verticais foram colocados $50 \mu \mathrm{L}$ do antifúngico padrão, sendo o cetoconazol, em diferentes concentrações variando entre $16 \mu \mathrm{g} / \mathrm{mL}$ até $0,5 \mu \mathrm{g} / \mathrm{mL}$.

Finalmente, $100 \mu \mathrm{L}$ do inóculo foram colocados em todos os poços. Foi utilizado como controle negativo o meio RPMI 1640 com o inóculo. Como controle positivo foi utilizado as CIM do antifúngico padrão e do extrato. As placas de dermatófitos foram incubadas a $36{ }^{\circ} \mathrm{C}$ durante 6 dias. Os ensaios foram realizados em duplicata.

O sinergismo foi determinado como o índice de FICI $<$ ou $=0,5$, efeito aditivo quando o índice é de FICI= 0,5 a 1,0, indiferente com FICI> 1,0 e $<$ ou $=4,0$ e antagonismo com FICI $>4,0$. (WHITE et al., 1996)

\section{Atividade hemolítica}

A atividade hemolítica do extrato bruto foi determinada em células humanas centrifugadas por 10 min e distribuídas em placas de 96 poços. Após a remoção do plasma, o sedimento contendo os glóbulos vermelhos foi lavado com $50 \mu \mathrm{L}$ de PBS gelado e levado a centrifuga por 5 minutos, esse procedimento foi repetido por cinco vezes. Posteriormente, foi colocado cerca de $100 \mu \mathrm{L}$ de PBS em cada tubo eppendorf adicionando $40 \mu \mathrm{L}$ do extrato diluído em DMSO e feitas diluições seriadas num intervalo de concentração de $0,03-2,5 \mathrm{mg} / \mathrm{mL}$.

As suspensões resultantes foram incubadas em um agitador refrigerado por $60 \mathrm{~min}$ a $37{ }^{\circ} \mathrm{C}$. Após o tempo de incubação, as amostras foram centrifugadas durante $2 \mathrm{~min}$ e os sobrenadantes foram transferidos para placas de 96 poços para a realização da leitura por absorbância de $540 \mathrm{~nm}$. Foi utilizado o leitor multiplacas Bio tek Synergy HT. Serviram como 
controle positivo e negativo o Triton X-100 a $1 \%$ e $4 \%(\mathrm{v} / \mathrm{v})$ em PBS com hemácias não tratado, respectivamente. $\mathrm{O}$ teste foi realizado em triplicata e a percentagem de hemólise foi calculada utilizando a seguinte expressão:

$\left(\mathrm{Abs}_{540 \mathrm{~nm}}\right.$-tratados- $\mathrm{Abs}_{540 \mathrm{~nm}}$ não tratado)

( $\mathrm{Abs}_{540 \mathrm{~nm}} 1 \%$ deTritonX-100-Abs $540 \mathrm{~nm}$ não tratado)

Ensaio de letalidade com Artemia salina Leach

O ensaio de toxicidade contra Artemia salina Leach foi realizado segundo método proposto por Meyer et al. (1982). Os ovos de $A$. salina foram incubados em uma salina artificial com 23 g/L de sal marinho e 0,7 g/L de bicarbonato de sódio em água destilada, à temperatura ambiente entre $22-29^{\circ} \mathrm{C}$, por um período de 48 horas em uma aquário adaptado com um compartimento escuro e outro claro. Utilizando-se uma fonte de luz em que os náuplios foram atraídos para a luz, recolhidas com pipeta Pasteur e transferidas para um Becker com água salina. Foram preparadas diluições seriadas a partir de $20 \mathrm{~mL}$ da amostra com clorofórmio $\left(\mathrm{CHCl}_{3}\right)$ para a obtenção das concentrações finais de 1000, 100, 10 e 1 ppm. Foi utilizado um controle negativo contendo apenas $100 \mu \mathrm{L}$ de DMSO e 4,9 mL de solução salina e um controle positivo com dicromato de potássio $\left(\mathrm{K}_{2} \mathrm{Cr}_{2} \mathrm{O}_{7}\right)$ e solução salina. Em seguida foram adicionadas em tubos de ensaio 10 larvas contendo $5 \mathrm{~mL}$ de cada uma das soluções testadas e do controle. Os ensaios foram realizados em triplicata e para a contagem do número de náuplios foram considerados mortos aqueles que permanecerem imóveis por mais de 10 segundos após agitação suave dos tubos (LHULLIER et al., 2006).

\section{RESULTADOS E DISCUSSÃO}

Para o teste de microdiluição em caldo frente à levedura e dermatófitos demonstram atividade antifúngica, sendo observada por meio da determinação do CIM e do MFC frente a $T$. rubrum e C. albicans (Tabela 1).

$\mathrm{O}$ extrato bruto e a fração clorofórmio apresentaram $\mathrm{CIM} \geq 0,625 \mathrm{mg} \cdot \mathrm{mL}^{-1}$ e $\mathrm{MFC} \geq 1,25$ $\mathrm{mg} \cdot \mathrm{mL}^{-1}$ contra $T$. rubrum sendo os melhores resultados encontrados. Os testes mostraram que o extrato não inibiu o crescimento de nenhuma das leveduras ensaiadas.

Para a espécie de $M$ peruiferum L.f não há relato na literatura de atividade antifúngica, sendo este trabalho pioneiro em descrever pela primeira vez a atividade in vitro do seu extrato da casca frente às cepas dermatófitos de T. rubrum.

Já Matos Neto (2013) descreve que M. peruiferum L.f. apresenta atividade antimicrobiana para as cepas de Staphylococcus aureus (ATCC 25923), Enterococcus faecalis (ATCC 29212), Klebsiella pneumoniae, Aeromonas caviae, Pseudomonas aeruginosa, Víbrio parahaemolyticus, e Escherichia coli. Todos os micro-organismos provenientes de alimentos. A cabreuvina é o composto mais importante do extrato de $M$. peruiferum, com atividade antibiótica contra $H$. pylori. (OHSAKI et al., 1999).

De acordo com a literatura consultada, foram encontrados resultados do extrato de $M$. peruiferum L.f. para atividade antibacteriana. Segundo Gonçalves et al. (2005 e 2007), M. peruiferum apresenta atividade para Escherichia coli, Enterobacter aerogenes, Klebsiella 
pneumoniae, Providencia spp, Proteus mrabilis, Pseudomanas aeruginosa, Staphylococus aureus e Salmonella Typhimurium, e foi sensível para Streptococcus pyogenes, Shigella flexneri,
Shigella sonnei, Staphylococcus epidermidis $e$ Staphylococcus spp usado como coagulase negativa. Sendo todos os micro-organismos obtidos de infecções clínicas.

Tabela 1. Concentração Inibitória Mínima (CIM) e Concentração Fungicida Mínima (CFM) do extrato de $M$. peruiferum L.f. (mg.mL ${ }^{-1}$ ) frente ao T. rubrum e C. albicans

\begin{tabular}{|c|c|c|c|c|c|}
\hline \multirow[t]{2}{*}{ Microrganismos } & \multirow[t]{2}{*}{ Extratos } & \multirow{2}{*}{$\begin{array}{c}\text { MIC } \\
(\mathrm{mg} / \mathrm{mL})\end{array}$} & \multirow{2}{*}{$\begin{array}{l}\text { MFC } \\
(\mathrm{mg} / \mathrm{mL})\end{array}$} & \multicolumn{2}{|c|}{ Controles $(\mathrm{mg} / \mathrm{mL})$} \\
\hline & & & & Anfotericina B & Cetoconazol \\
\hline \multirow{4}{*}{$\begin{array}{l}\text { Trichophyton rubrum } \\
\text { CEMM 05.1.034 }\end{array}$} & Bruto & 0,625 & 1,25 & - & 2,5 \\
\hline & Clorofórmio & 0,625 & 1,25 & - & 2,5 \\
\hline & Acetato & 1,25 & 2,5 & - & 2,5 \\
\hline & Metanol & 10 & NI & - & 2,5 \\
\hline \multirow{4}{*}{$\begin{array}{l}\text { Candida albicans } \\
\text { CLS 17:11 }\end{array}$} & Bruto & NI & NI & 1,0 & - \\
\hline & Clorofórmio & NI & NI & 1,0 & - \\
\hline & Acetato & $\mathrm{NI}$ & NI & 1,0 & - \\
\hline & Metanol & NI & NI & 1,0 & $\overline{-}$ \\
\hline
\end{tabular}

Concentração Inibitória Mínima (CIM) e Concentração Fungicida Mínima (CFM). NI: Não identificado

Fonte: $\mathrm{O}$ autor

Tabela 2-Sinergismo do extrato de $M$ peruiferum L.f. com o Cetoconazol frente ao T. rubrum

\begin{tabular}{lcccccc}
\hline Extrato/ droga & \multicolumn{3}{c}{ T. rubrum $(05.1 .034)$} & \multicolumn{3}{c}{ T. rubrum (6753) } \\
\hline Bruto & $\begin{array}{c}\text { MIC } \mu \mathrm{g} / \mathrm{mL} \\
\text { (sozinho) }\end{array}$ & $\begin{array}{c}\text { MIC } \mu \mathrm{g} / \mathrm{mL} \\
\text { (combinado) }\end{array}$ & FIC Index & $\begin{array}{c}\mathrm{MIC} \mu \mathrm{g} / \mathrm{mL} \\
\text { (sozinho) }\end{array}$ & $\begin{array}{c}\text { MIC } \mu \mathrm{g} / \mathrm{mL} \\
\text { (combinado) }\end{array}$ & $\begin{array}{c}\text { FIC } \\
\text { Index }\end{array}$ \\
Cetoconazol & 625 & 39 & 4,06 & 1.250 & 39 & 4,03 \\
Fração acetato & 1,0 & 4,0 & & 2 & 8 & \\
Cetoconazol & 2.500 & 39 & 2,01 & 1.250 & 9,7 & 1,00 \\
Fração metanólica & 1,0 & 2,0 & & 2 & 2 & \\
Cetoconazol & 10.000 & 625 & 4,06 & 10.000 & 2.500 & 4,25 \\
\hline
\end{tabular}

Fonte: $\mathrm{O}$ autor

Em relação à atividade modulatória, foram utilizadas as cepas de $T$. rubrum (05.1.034) e T. rubrum (6753), os resultados estão dispostos na tabela 2. O ensaio de combinação do extrato de $M$. peruiferum L.f com o antifúngico padrão cetoconazol mostrou que houve uma redução significativa nos valores de CIM em ambas as além do expressivo aumento do CIM do cetoconazol da cepa de $T$. rubrum (05.1.034) de 1,0 para 4; 1,0 para 2,0 e 2,0 para 8,0 em relação ao extrato bruto, fração acetato e metanólica, respectivamente. Enquanto que para a cepa de $T$. rubrum (6753), o antifúngico padrão variou entre 2,0 a 8,0 para o extrato bruto e para a fração metanólica. A partir destes valores, foi possível calcular o índice de concentração inibitória fracionária (FICI) que mostrou efeito antagônico no ensaio da atividade para a cepa de T. rubrum (05.1.034) em relação ao extrato bruto e a fração metanólica com FICI de 4,06, enquanto que a fração acetato mostrou efeito indiferente com FICI de 2,01.

Para a cepa de T. rubrum (6753), apresentou efeito antagônico para o extrato bruto e a fração metanólica com variação da FICI de 4,03 a 4,25. Em relação à fração acetato, mostrou-se efeito aditivo com FICI de 1,00.

$\mathrm{O}$ teste para determinar a atividade hemolítica in vitro do $M$. peruiferum L.f. 
mostrou que nas concentrações de 0,039; 0,078; 0,$156 ; 0,312 ; 0,625 ; 1,25$ e $2,5 \mathrm{mg} / \mathrm{mL}$, a percentual de hemólise variou entre 0,19\% até 40,88 \% (gráf.1). constatado na concentração de $20 \mu \mathrm{g} . \mathrm{mL}-1$ sendo responsáveis para a redução significativa $(\mathrm{p}<0,001)$ de aproximadamente

Gráfico 1- Concentrações da atividade hemolitica de $M$ peruiferum L.f

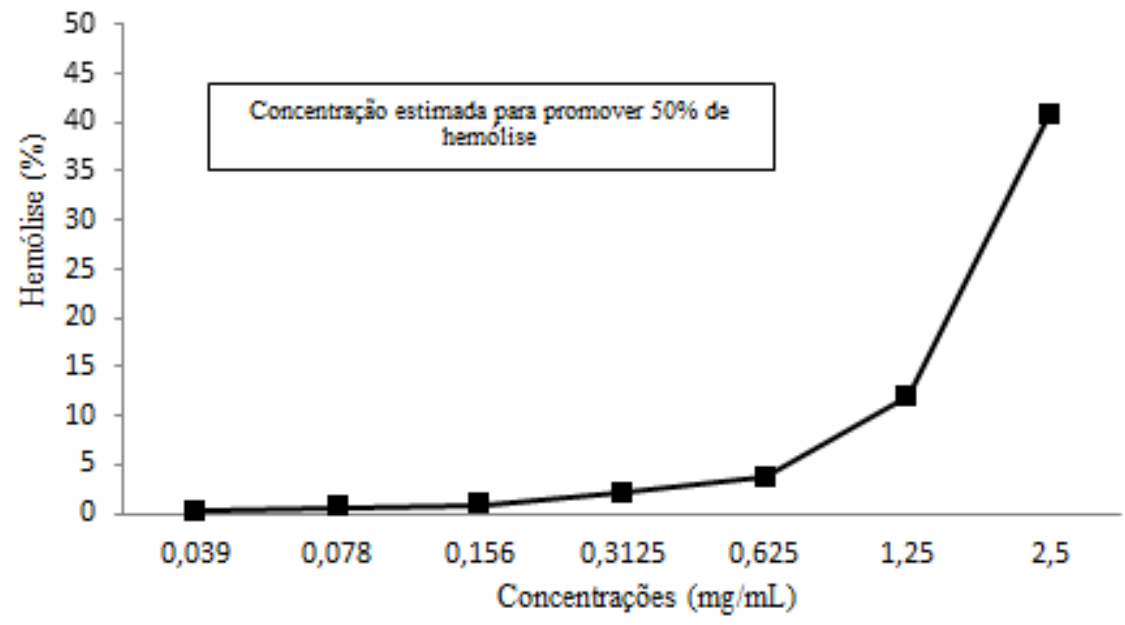

$\mathrm{Na}$ comparação do valor de $\mathrm{IC}_{50}$ da atividade hemolítica com o CIM, indicou que a concentração do extrato responsável pela atividade fungicida e fungistática é menor em comparação com a concentração necessária para danificar as células vermelhas do sangue por ruptura da sua membrana.

Não há registro na literatura sobre atividade hemolítica da espécie estudada. Então, podemos comparar os resultados encontrados com relação à Anfotericina B. Segundo Oliveira (2012), foi verificado que determinados produtos tem a capacidade de inibir a hemólise induzida pela anfotericina B na concentração de $16 \mu \mathrm{g} \cdot \mathrm{mL}^{-1}$.

Destacamos, ainda, que a AmB numa concentração de $40 \mu \mathrm{g} \cdot \mathrm{mL}^{-1}$ mostra-se efeito tóxico sobre os leucócitos causando a redução da viabilidade celular e o efeito citotóxico da AmB em células Vero foi
$30 \%$ na viabilidade celular.

No bioensaio de toxicidade do extrato de M. peruiferum L.f com larvas de A. salina, a dose letal capaz de matar $50 \%$ das larvas $\left(\mathrm{CL}_{50}\right)$ foi de $403,16 \mu \mathrm{g} / \mathrm{mL}$. Os ensaios com náuplios de A. salina são utilizados devidos o seu rápido resultado na qual correlaciona com potenciais atividades biológicas, sendo assim um indicativo de atividade biológica (MCLAUGHLIN et al., 1998). O valor de $\mathrm{CL}_{50}$ do M. peruiferum L.f menor ou igual a $1000 \mu \mathrm{g} / \mathrm{mL}$ indica que ele possui atividade biológica considerada significativa (MEYER et al., 1982).

\section{CONCLUSÃO}

Vale salientar que o extrato bruto assim como as frações clorofórmio, acetato de etila e metanólica, apresentaram potencial antifúngico frente às cepas dermatofíticas de $T$. rubrum, justificando, assim a sua utilização na medicina para o tratamento de infecção. 
Em relação à atividade hemolítica o extrato é citotóxico em relação ao CIM e ao CFM, já para o teste de toxicidade contra $A$. salina mostrou que o extrato possui toxicidade ativa, sugerindo a utilização desse extrato para várias atividades biológicas, como antileishmania e antitumoral.

\section{REFERÊNCIAS}

BRASIL. Ministério da Saúde. Secretaria de Atenção à Saúde. Departamento de Atenção Básica. Práticas integrativas e complementares: plantas medicinais e fitoterapia na Atenção Básica/Ministério da Saúde. Secretaria de

Atenção à Saúde. Departamento de Atenção Básica. - Brasília: Ministério da Saúde, 2012.

FONTENELLE, R. O. S.; MORAIS, S. M.; BRITO, E. H. S.; KERNTOPF, M. R.; BRILHANTE, R. S. N.; CORDEIRO, R. A.; TOMÉ, A. R.; QUEIROZ, M. G. R.; NASCIMENTO, N. R. F.; SIDRIM, J. J. C.; ROCHA, M. F. G. Chemical composition, toxicological aspects and antifungal activity of essential oil from Lippia sidoides Cham. J Antimicrob Chem.v.59, p. 934-940, 2007.

FONTENELLE, R. O. S.; MORAIS, S. M.; BRITO, É. H. S.; BRILHANTE R.S. N.; CORDEIRO, R. A.;NASCIMENTO, N.R. F.; MENDONÇA, M. R. K.; SIDRIM, J. J. C.; ROCHA, M. F. G. Antifungal activity of essential oils of Croton species from the Brazilian Caatinga biome. Journal of Applied Microbiology. v. 104, p. 1383-1390, 2008.

GONÇALVES, A.L.; FILHO, A. A.; MENEZES, H. Estudo comparativo da atividade antimicrobiana de extratos de algumas árvores nativas. Arq. Inst. Biol. v.72, n.3, p.353-358, 2005.

GONÇALVES, A.L. Estudo da atividade antimicrobiana de algumas árvores medicinais nativas com potencial de conservação/recuperação de florestas tropicais. 2007. 141f Tese de doutorado. Instituto de

Biociências, Universidade Estadual Paulista "Júlio de Mesquita Filho", Rio Claro, 2007.
Neste contexto, a planta mostra-se como uma fonte promissora de matéria-prima na produção de novos medicamentos fitoterápicos, pois a espécie estudada mostra-se com relevantes atividades biológicas.

LHULLIER C, HORTA PA, FALKENBERG M 2006. Avaliação de extratos de macroalgas bênticas do litoral catarinense utilizando o teste de letalidade para Artemia salina. Rev Bras Farmacogn 16: 158-163.

LORENZI, H.; MATOS, F. J. A. Plantas Medicinais no Brasil: nativas e exóticas. Nova Odessa: Plantarum, 2008. 576p.

MCLAUGHLIN, J. L., ROGERS, L.,ANDERSON, J.E. The Use of Biological Assays to Evaluate Botanicals. 32(2):513524.1998

MEYER, B. N., FERRIGNI, N. R., PUTNAN, J. E., JACOBSEN, L. B., NICHOLS, D. E., Mcl. AUGHLIN, J. Brine shrimp: A convenient general bioassay for active plant constituents. Journal of Medical Plant Research, v. 45, n.1, p. 31-34, 1982.

OHSAKI, K., MORIMITSU, T., ISHIDA, Y., KOMINAMI, TAKAHASHI, N. Expression of the Vax family homeobox genes suggests multiple roles in eye development. Genes Cells 4, 267-276, 1999.

OLIVEIRA, V. M. Associação entre Camellia sinensis e anfotericina b: atividade antifúngica e citotoxicidade. Dissertação de Mestrado.

Universidade Estadual do Centro-Oeste. 2

SILVA, N. C. C.; FERNANDES JR., A.

Biological properties of medicinal plants: a review of their antimicrobial activity. J. Venom Anim. Toxins incl. Trop. Dis., v. 16, n. 3, p. 402-413, 2010.

\section{WORLD HEALTH ORGANIZATION} (WHO).The world medicines situation 2011: traditional medicines: global situation, issues and challenges. Geneva: WHO, 2011. 12p. 
WORLD HEALTH ORGANIZATION. Wound Healing Managements. Disponível em:http://www.who.int/hac/techguidance/tools/g uidelines_prevention_and_manag ment_wound_infection.pdf. Acesso em: 20 set. 2013.

WHITE, R.L.; BURGESS, D.S.; MANDURU, M.; BOSSO, J.A. Comparasion of three different in vitro methods of detecting synergy: Time-kill, checkerboard and E-test. Antimicrobial agents and chemotherapy. v. 40, p.1914-1918,1996.

\section{Rafael Pereira}

Mestre em Biotecnologia de Recursos Naturais-UFC. Doutorando em Biotecnologia em Recursos NaturaisUFC.

Francisco Ângelo de Matos Neto

Biólogo pela da Universidade Estadual Vale do Acaraú

\section{Francisca Lidiane Linhares de Aguiar}

Mestra em Recursos Naturais-UECE

Doutoranda em Ciências Farmacêuticas-UFC

\section{Elnatan Bezerra de Souza}

Mestre em Botânica -UFRP.

Doutor em Ciências - Botânica pela UEFS.

Professor adjunto da Universidade Estadual Vale do Acaraú.

\section{Hélcio Silva Santos}

Mestre e doutor em Química Orgânica-UFC

Professor adjunto da Universidade Estadual Vale do Acaraú.

\section{Carolina Sidrim de Paula Cavalcante}

Mestra em Ciências Veterinárias-UECE

Doutora em Ciências Farmacêuticas-UFC

\section{Raquel Oliveira dos Santos Fontenelle}

Mestra e doutora em Ciências Veterinárias-UECE

Professora adjunta da Universidade Estadual Vale do Acaraú. 